\title{
What Foreign Language Teachers Should Know about Language Attrition
}

\author{
Malgorzata SZUPICA-PYRZANOWSKA \\ University of Warsaw \\ E-mail: m.szupica-pyrz@uw.edu.pl \\ Katarzyna MALESA \\ University of Warsaw \\ E-mail: k.malesa@uw.edu.pl
}

\begin{abstract}
The long-term goal of foreign language (FL) learners is to reach communicative competence. The objective of language teachers is to assist and support learners in accomplishing this goal. However, the task may be challenging, especially, when considering foreign language taught in the context of instructed learning. The advent of new technologies, the emergence of learner-centered teaching, and the emphasis on authentic language do not always warrant a desirable outcome. Foreign language learners often reach a plateau and do not progress as expected. Loss of non-native language skills in the L1 environment, e.g. loss of foreign languages learned at school, is a fact. Foreign language learners may be prone to attrition due to insufficient input, low frequency of language use outside the classroom or lack of adequate motivation. Therefore, it is imperative to raise FL teachers' awareness and draw their attention to the problem of language loss occurring in a formal context. Teachers should not only facilitate language learning but also prevent language forgetting which, if prolonged, may cease development and lead to attrition. By drawing attention to FL attrition, we aspire to bridge the gap between linguistic research and language classroom pedagogy. The aim of the current paper is to identify and discuss some of the instructional, cognitive, and personal factors contributing to foreign language attrition. Practical implications are discussed that could not only improve language teaching, but also influence more efficient, attrition-free curriculum design.
\end{abstract}

Keywords: foreign language attrition, memory, attention, instructional considerations, FL learner autonomy, FL teachers

\section{Introduction}

The process of language attrition has been studied extensively in the context of first and second language acquisition (M.S. Schmid/ T.H. Mehotcheva 2012, H. Seliger/ R. Vago 1991). However, still not enough attention is given to the attrition of foreign languages taught formally. As counterintuitive as it may appear, the formal context in which foreign languages are taught may be the source of language loss. Many learners who studied foreign languages in (junior) high school or college, lost the ability to hold a meaningful conversation with a native speaker once they graduated or completed a course and were no longer exposed to the language they had studied formally (T. Reilly 1988). In extreme cases, the retained knowledge is receptive only. For many learners, however, the onset of attrition could have occurred while they were 
still in school and, thus, in the context of (active) learning. Large classrooms, lack of group homogeneity, insufficient input, low frequency of language use, and nonauthentic language - all this could potentially trigger foreign language loss while the language is being acquired. In the paper, we address classroom-related and cognitive aspects potentially detrimental to the process of language learning and possibly contributing to foreign language attrition: the intensity of instruction, instructional considerations, learner profile, developmental considerations, attention span, memory, learner autonomy, and learner's attitude towards foreign language learning.

\section{What is attrition?}

Everything that is acquired could be potentially lost. Languages are lost under different circumstances. A pathological language loss, whether temporary or permanent, can occur after a traumatic brain injury or can be stroke-related, whereas non-pathological language loss occurring in healthy individuals is triggered by a language disuse (or insufficient language use) and is maintained once the language disuse is prolonged. Major features of non-pathological attrition, the scope of the present inquiry, include the following: shrinking phonetic inventories, simpler phonetic rules, inadequate grammatical flexibility, smaller lexical repertoires or lack of automaticity in the overall language use (J. Holmes 2008)

Thus far, the non-pathological language loss has been reported in three different contexts :1. An immigrant who is a speaker of the language not spoken natively in the new country of residence and who slowly loses his native language; 2 . A speaker of a language who lives in a place where a different language is considered more prestigious or sought-after. 3. A learner who studied a language at school and who loses the language owing to the lack of opportunity to practice it outside classroom (T. Reilly, 1988). Recently, M. Szupica-Pyrzanowska and K. Malesa (2017) identified a yet different group whose language competence is potentially susceptible to language loss, foreign language teachers. The preliminary results obtained in the study indicated that: a. the level of language attrition awareness among FL teachers is low, b. FL teachers are more likely to relate attrition to their students' rather than to their own language skills, c. FL teachers who teach very young learners are more prone to attrition than FL teachers whose students are teenagers and adults, d. those who teach young FL learners report to be less motivated to maintain their language skills on a regular basis. In a similar vein, T.M. Włosowicz (2017) tested 39 non-native foreign language teachers to 1 . determine how they prevent their language loss, 2 . evaluate their attitude towards correctness, and 3. identify language domains which are more prone to attrition. The participants were asked to complete a grammar/vocabulary test and fill out a detailed questionnaire. Also, the participants were asked to assess the difficulty of different grammar components included in the test. Overall, the results indicate that many FL teachers tend to consider fluency to be more important than accuracy, they have no time to work towards maintaining or improving their language skills, they admit to forgetting both grammar and vocabulary once they graduate, they are not always certain whether what they have said or written in English is correct, and clearly some teachers believe that they became less fluent in English in the course 
of their work. Moreover, the participants reported on using different language maintenance strategies so as to preserve their language skills. The most frequently used were the following: reading books/magazines/newspapers in English, seeking opportunities to interact with native speakers, listening to English radio programs, chatting online with English speakers, watching movies, and doing exercises from textbooks for advanced students. In addition, it was observed that foreign language teaching can be a potential source of language attrition because FL teachers need to simplify their own language for the sake of their students, and they are exposed to a myriad of errors made by their students on a regular basis.

In the present paper, our main interest lies in one of the aforementioned instances of attrition, namely a foreign language student who learns a non-native language in a formal context. Contrary to common sense, the quality of formal FL learning in many state schools does not always guarantee a successful target-like production or does not promote acquisition. Students are not only heterogeneous in their aptitude and achievements but also in their need to practice language outside classroom and work towards maintaining their FL knowledge. Therefore, they may experience attrition in different ways. Numerous factors could potentially contribute to this state of affairs. In large mixed-ability language classrooms weak students can easily go unnoticed and their language needs may not be adequately addressed. Lack of necessary exposure to the target language and insufficient practice may foster speaking anxiety and ultimately may lead to a negative attitude towards the foreign language studied. In such an environment weak students become withdrawn and do not progress as expected. So, either they do not learn enough or they make progress at a very slow pace. And if the language is not rehearsed, it is not retained and begins to diminish. Even good students when not motivated and encouraged may potentially find themselves on the verge of language loss, regress, begin to lose what they learned previously and subsequently reach the phase where their language achievements are modest. FL learners may fluctuate on a developmental continuum going back and forth between intermediate stages shifting either toward the source or the target language. All of this leads to the conclusion that in the formal context FL students may not always have the opportunity to use the language they learn as much as necessary.

\section{Instructional considerations}

T. Reilly (1988) pointed that "curriculum design and instructional methods in foreign language teaching are different if the aim is to foster language rather than just to achieve a certain level of competence as the result of taking the class" (p.2). This is the educational reality repeatedly observed in many Polish state schools in which foreign language classes promote the ability to take and pass a language test rather than the ability to freely communicate in a non-native language. Consequently, the majority of learners who are many years post-onset lacks basic FL communicative skills. The reasons are twofold: either an insufficient progress made by learners or a regress sufficient enough to lose one's language skills. FL teachers ought to be vigilant and pay close attention to those students who either abruptly or gradually shift in their 
language use and begin to lag behind their peers. The insufficient progress may be represented by low grades, an abrupt student's withdrawal, a lack of participation and commitment to class or even a negative attitude toward the language being learned. The lack of progress may be a prerequisite to language attrition. We argue that attrition is a process and as such proceeds in stages which result in different degrees of language loss. M. Szupica-Pyrzanowska and K. Malesa (2017) propose three intermediate phases in the process leading from a certain stage of acquisition to attrition: stagnation, plateau, and regression. Stagnation is understood as language inertia during which there is no (sufficient) contact with the target foreign language. Extended stagnation results in a plateau, a phase of limited variation where hardly any new material is added to the learner's language repertoire. During the plateau period, language development slows down considerably and may come to a halt. If sustained, plateau may turn into a full-fledged regression which over time develops into attrition. This three-phase process is, to a certain extent, reversible if the conditions for language enhancement are favorable.

Moreover, not all language skills are equally prone to being lost. By the same token, not all learners will show the same pattern of decline across different skills. Productive skills (e.g., speaking and writing) are known to be less resistant to attrition than receptive ones (e.g., listening and reading). Consequently, language curricula based on oral skills foster language maintenance at the same time. However, language curricula should target not only productive skills but comprehension and writing as well. In contrast to encoding spoken language, decoding the written language does not have to be instantaneous. The reader can decode the text at his own pace and revisit it for better understanding which in a long run teaches learners diligence, promotes selfinstruction, and the need for reexamination (T. Reilly 1988).

Furthermore, receptive skills are acquired prior to productive skills (S. Lamb 1999). The reception-before-production pattern is observed in different populations: children acquiring their native tongue or young and adult second/foreign language learners. In all groups the same pattern has been observed, understanding of complex syntactic structures preceded their production while comprehension of less frequently used lexical items occurred prior to their application in the course of language acquisition and often remained long after instruction was interrupted. This is important for language pedagogy. Receptive abilities should never be taken for granted and marginalized in language classrooms because: 1. Students whose language curricula target primarily productive skills may decline more rapidly or their attrition may be more extensive than those students whose language instruction also emphasizes receptive skills (e.g., comprehension, writing); 2. Auditory systems supervise articulatory outcome; 3 . The receptive system controls production. 4 . Receptive repertoires are bigger than productive ones; on average, people have bigger lexicons for comprehension than for production. In addition, early studies on foreign language attrition indicated that language disuse during summer vacation did not affect students' understanding of grammar and lexicon (G. Scherer 1957, P.C. Smythe/ G.C. Jutras/ J.R. Bramwell/ R.C. Gardner 1973). Unlike comprehension, 
language production diminished significantly after a summer vacation period as it had been reflected in shorter utterances and more frequent errors (A.D. Cohen 1974).

Finally, we will illustrate the importance of balanced skill development (including productive and receptive skills) with the example of lexical acquisition. Forgetting is a natural part of learning. Both students and teachers are aware of that fact. Nonetheless, it is worth noticing that words known only receptively are more likely to be forgotten than the words that students know productively. That is why teachers should provide students with multiple exposure to any new utterance in the course of FL lessons. Previous research indicates that in order to learn a word, one needs to meaningfully repeat it between 5 and 20 times (N. Schmitt 2007). If students do not practice retrieving newly acquired lexical items and if lexical recycling is neglected, the utterances or lexical items will be forgotten or not easily used in spontaneous production. Accordingly, lexical recycling is an inherent part of vocabulary practice in the FL classroom (N. Schmitt 2007). Frequency and recency of lexical use as well as a contextualized presentation of words prevent lexical attrition.

Identification of attrition may not always be easy and may be mistaken for chunked learning. Likewise, identification of the processes that precede attrition (e.g., stagnation, plateau, regression) may also be difficult. For instance, in a classic study K. Hakuta (1974) presented the case of Uguisu, a Japanese child learning English who was able to correctly utter the following Yes-No questions: Do you know? Do you have coffee? Do you want this one? The aforementioned examples appeared to be well-formed and thus suggested that the learner had mastered the syntactic structure including inversion and do-support. However, when she started learning Whquestions an interesting pattern emerged in her speech production: What do you doing, this boy? (meaning "What is this boy doing?"), What do you do it, this froggie? (meaning "What is this froggie doing?"), What do you doing? (meaning "What are you doing?"), What do you do drinking, her? (meaning "What is she drinking?"). On the surface, it seemed that Uguisu regressed and extended the Simple Present tense structure to the Present Progressive tense. Further, she seemed to have unlearned what she had apparently known earlier. On closer inspection, however, it became evident that what previously appeared correct was simply correct by chance. This stage of Uguisu's language development is known as chunked learning. The term refers to a strategy used by non-native speakers occurring at a certain stage of lexical/syntactic development at which a single unparsed element is used of what may otherwise be considered two or more elements by a native speaker. Uguisu did not use do you as an element of Yes-No questions but simply learned it as a chunk which might have been used frequently in her language environment. Such non-target syntactic structures are pre-fabricated, ready-made patterns which will eventually be "unpacked" into its components of do and you. Although to the untrained ear/eye such a process may appear to resemble regression, this is in fact U-shaped learning masked as regression. U-shaped learning is a natural phase of cognitive development which includes an initial, temporary, accidental target-like production followed by an erroneous phase and a recovery manifested as correct forms. The ramifications of Ushaped learning extend beyond Uguisu and the Japanese language and could be 
observed in other populations representing different L1s. In Uguisu's case, like in the case of many foreign language students, the target performance ultimately recovers and stabilizes. A prerequisite to an adequate treatment of attrition is an appropriate identification of different phenomena taking place in the classroom. Teachers ought to be able to distinguish between U-shaped learning and early symptoms of preattrition phases (e.g., stagnation, plateau, regression) and should not be lost, in what appears to be, the maze of choices.

\section{The intensity of instruction}

Not only the prolonged exposure to the language being studied leads to proficiency and desirable outcomes, but also the intensity with which language is learned. Early research shows that students enrolled in a one-year intense course of French outperformed those who had the same number of hours and studied the language over the course of two years, but less intensively (H.H. Stern 1976). Further, intensive language classes are said to be more conducive to language retention (H.P. Edwards 1976).

R. Serrano (2012) comprehensively reviewed studies whose results suggested that time distribution is an important factor in successful language acquisition. Clustering the hours of language teaching/learning rather than stretching them over time proved beneficial for learners. L. Collins et al. (2012) pointed that in intensive courses language success depends on the time dedicated to studying. Specifically, two timerelated factors are significant, its distribution and quality. Further, L. Collins /J. White (2012) investigated the influence of intense language courses on various aspects of proficiency in a longitudinal study. They inquired whether individual L2 differences at the outset of the study would be sustained throughout the intensive course or whether the elimination of the intensity factor would allow those students who initially lagged behind their more proficient counterparts to accelerate and catch up. It turned out that half-way through the intensive course the less fluent students began to reduce the difference in proficiency while at the end of the program both groups showed comparable levels of knowledge on some of the tasks. Overall, the study reveals that at the early stages of acquisition intensive L2 courses may diminish the role of individual differences among beginner learners (e.g., language aptitude) in the formal learning environment. Without a doubt, intensity alone may not suffice to assure a desirable learning outcome. L. Collins et al. (2012) emphasize the need for attention to those aspects of input which learners find particularly difficult.

In the context of second language acquisition, J. Netten/ C. Germain (2000) identified intensity as a three-fold concept including: 1. a concentration of teaching time related to a particular scheduling arrangement that permits a sequence of language classes; 2. an increase in teaching time; 3. reorientation of the curriculum, itself a complex notion including condensing and enriching of the regular curriculum as well as the use of an interactive approach. The notion of enrichment of the previously used language curriculum is especially relevant to the issue of language loss. The enrichment is understood in terms of significant changes in the content of a curriculum particularly regarding a more detailed presentation, an in-depth thorough 
examination of topics discussed in language classes, a theme-based method incorporating students' interests, and an integrated approach to language teaching that includes elements from different subject areas (e.g., science, humanities). In order to enrich language curricula, J. Netten/C. Germain do not only suggest a series of related connecting language activities that provide enough material for the extended class time that goes beyond the 45-minute periods usually dedicated to language instruction in many schools, but they also stress the importance of a predominant use of foreign language in authentic situations. To be successful students must use language actively in genuinely authentic communicative situations. Intensity could be further enhanced by an interactive pedagogy and projects. It has to be emphasized that all of this is done to achieve a linguistic goal and foster communication in a foreign language. Such an intense pedagogical approach enables learners to use the language frequently, to practice complex structures, and to expand on one's cognitive (e.g., analysis, synthesis, making inferences, drawing conclusions, hypothesis testing), personal (e.g., independence, self-confidence, responsibility), social (e.g., accepting different points of view, the ability to cooperate) and organizational skills (e.g., planning work, using references). Students who learn languages intensively are more cognitively engaged in the process of acquisition than those involved in language learning that is less intense. For our purposes here we stress that intense foreign language courses foster acquisition and, thus, prevent attrition.

\section{Attention (span)}

Constant attention to stimuli is necessary for long-term retention of learning material (T.H. Carr/ T. Curran 1994). Attention is a three-part construct including: 1. alertness understood as a general eagerness to manage arriving information; 2. orientation or the management of attentional resources to different stimulus types; 3 . detection that relates to the perceptive registration and acknowledgment of different stimuli (M.I. Posner 1992, R.S. Tomlin/ V. Villa 1994). R.S. Tomlin/ V. Villa maintain that of the three components, detection alone is necessary for input processing as well as learning. By the same token, alertness and orientation only increase the likelihood that detection will take place, but are not as imperative. How do we make use of attention? Two features of attention are crucial in the process of learning: its limited capacity and selectivity. There is no consensus regarding the exact nature of selectivity, consequently two opposing views dominate the field, "early selection" and "late selection". Under the first view, there is a filter or bottleneck that preselects stimuli and permits only certain stimuli to be processed. The second approach assumes that all stimuli are processed at the same time; the selection part occurs later. Distribution of attention is a laborious process as we rarely perform just one task at the time. Numerous stimuli usually compete for our attention. Even though attention is of limited capacity and its allocation effortful, it changes as a function of arousal (D. Kahneman 1973, R.P. Leow/ M.A. Bowles 2005). What it means in practice is that learners can perform two tasks simultaneously as long as there is a sufficient level of arousal and a manageable level of task demands. Paying attention to two tasks concurrently is possible once we presume that there are multiple pools of attentional 
resources (parallel processing) rather than just one (serial processing). The level of challenge associated with performing two tasks at the same time is determined by the number of pools from which attentional resources are drawn. It would be harder to successfully perform two tasks drawn from the same pool (e.g., two linguistic tasks having a conversation and drafting an essay) that to do two tasks drawn from different pools (e.g., riding a bike and singing) (C.D. Wickens 1980, 1984, 1989). Yet, C.D. Wickens states that two different tasks performed simultaneously can be done effectively under one condition - when one of them has become automatized. Automaticity is essential for a proficient language use.

From a pedagogical point of view, learning requires attention, without it no learning will ever take place, and no teaching will ever be effective. Language learning cannot take place if students are distracted and not fully engaged. Capturing students' attention proves to be a challenge even for seasoned teachers. In order to energize students and help them listen actively, it is necessary to break up a lesson. No matter how good the speaker is, listening attentively can be challenging because the average attention span diminishes at 10-15 minutes into lesson. Learning a language requires not only attention but interaction as well. Breaking up lessons give students an opportunity to interact with their peers and gives the teacher a chance to monitor students' comprehension. Lesson segmentation may allow students to reflect on what they were exposed to, to see how much they actually absorbed, and to work toward developing metacognition. Consequently, students are more likely to hold themselves accountable for their learning and realize what they can do with the material they perceived auditorily. All of this promotes active listening. Language learners' recall of information is poor when they listen passively. If this is done routinely it may lead to stagnation and lack of development. Students who get stuck in their language development and do not grow as FL speakers may soon begin to attrite.

\section{Memory}

It is said that a healthy brain does not really "lose" anything; rather the previously acquired knowledge which is accessed sporadically, if ever, may become less available and its retrieval more effortful. Language learning involves various cognitive processes, one of which is memory. If memory is one of the cognitive ingredients active in language acquisition, then it is undoubtedly linked to the processes of language attrition and forgetting. Different memory types are conducive to foreign language learning: rote, working or long-term memory. Rote memorization is based on repetition and routine and as such it does not require reference to the meaning, context or association. Working-memory refers to the ability to manipulate information one is presently aware of or thinking about (e.g., remembering a phone number for the time it takes to dial it or a multi-stage calculation done in our head). It is brief and of limited capacity. Its duration and capacity can be increased by practice and chunking (e.g., grouping discrete elements into larger units). Students' long termmemory should be every language teacher's goal. A transfer from short-term to longterm memory is preceded by encoding and meaningfully combining the new 
information with existing one. Once this is done, the information is stored and consolidated in long term-memory. It does not mean, though, that the information committed to the long term memory will always be easily accessed. For that it is necessary to retrieve the stored information. If the information is not accessed frequently enough its retrieval becomes increasingly challenging and less automatic. Retrieval problems are responsible for forgetting. The goal of language acquisition is reaching (native-like) competence in the target language. Leaners have to know different mnemonic strategies so as to facilitate foreign language learning and to commit linguistic knowledge to their long-term memory. Foreign language teachers have to be aware of the role memory plays in language learning and design curricula to enhance students' memory for foreign language. To do so, one has to transfer linguistic knowledge - like any other knowledge - to long-term memory. Understanding the role of memory and forgetting is a prerequisite to understanding language attrition.

Working memory is limited and "fractioned" in a sense that it does not constitute a single entity but rather consists of different components (P. Shekan 2015). These include a central executive and phonological systems (for auditory processing), as well as visual spatial buffer systems. Attentive listening and intense exposure to the target language, although desirable in the context of foreign language learning, may strain students' working memory capacity. In general, foreign/second language interaction requires working memory operations and planning. Speech is, by nature, instantaneous and thus difficult as it happens in real time. While speaking we have to use our resources and knowledge of different language areas in a split second. In particular, we have to access and retrieve appropriate lexis, use correct morphological and syntactic structures, comply with relevant phonetic rules, be context appropriate. Finally, we have to constantly monitor the outcome, be listener-friendly, and organize our thoughts in a coherent way so as to convey what we intended to communicate. The task effortless in L1 acquisition is tedious and becomes a strain in a L2/ FL language. Undeniably, working memory is an asset in a foreign language classroom. Though, it is prone to variation. Proponents of capacity hypothesis, M.A. Just/ P.A. Carpenter (1992) investigated the way working memory capacity burdens language learners' comprehension. Under this view, storage (the repository from which information is retrieved) and processing (managing) of language material are facilitated by activation. The level of activation available in working memory varies among language learners. Individual differences in working memory capacity explain both qualitative and quantitative differences in various components of language comprehension (e.g. syntactic ambiguity). The larger working memory capacity, the better one's ability to distinguish between different meanings and numerous renderings.

In the present paper we argue that it is necessary to concentrate on working memory because of its significant influence on language acquisition, language processing, speech production, and interaction analysis. With regard to language, working memory is important for: language input (e.g., its parsing and semantic analysis), language output (e.g., accessing of lexical, syntactic, and morphological 
information, sentence building), resolving problems related to input and output processing, planning and analysis. In order to enhance students' working memory foreign language teachers are advised to implement different tasks, for instance narrative storytelling, event sequencing, and repetition (Z. Wang 2014, Z. Wang/ P. Shekan 2014). Understanding working memory-based limitations is crucial for language pedagogy. A successful use of resources needed for working memory warrants successful interaction. It is argued that interaction contains most of what is needed to support language development. Sustaining language development promotes acquisition and, in a way, prevents attrition.

\section{Learner profile (developmental considerations)}

Language classrooms do not constitute homogenous populations. Students differ in terms of their commitment, strategies used to deal with anxiety, levels of speaking anxiety, diligence, effort put into learning or a linguistic inclination known as language aptitude among others. Therefore, they differently succeed in being fluent speakers. Language learners of different age pose different challenges and represent different success rates. Adult language learners whose onset of foreign language learning occurred post puberty or later in life, are more likely to transfer their knowledge of native language. Their first language may interfere with the new one. For that reason language curricula have to be custom-made, designed for the population taught. For example, L1 Polish learners of English may struggle with the English phonetic system (e.g, vocalic length, interdental consonants, rhotic " $r$ "), syntactic mechanisms (e.g., inversion), morphosyntactic rules (e.g., the third person singular indicating subject-verb agreement), semantic aspects (e.g., reciprocals teachlearn, borrow-lend), pragmatic rules (e.g., incorrect speech acts, extension, erroneous understanding of veiled requests)

In our discussion of language attrition certain developmental considerations, such as learner types, have to be briefly addressed. Needless to say adult language learners differ in many respects from their younger counterparts. They approach the language learning process with different expectations and motivation. Adult seem better equipped to the process of language acquisition. They use personal experience as a resource and tool and are often self-directed. Unlike youth, adults have good analytical, problem-solving, as well as metacognitive and metalinguistic skills. Also, they more rapidly grasp abstract notions. However, adult language learners are known for their initial advantages and short-lived gains only while children reach and maintain ultimate attainment as a result of prolonged and intensive exposure. Children have better phonology but older language learners often achieve better L2 syntax (M. Long 1990). Foreign language programs that capitalize on the aforementioned developmental differences do not only facilitate acquisition but also help prevent attrition.

\section{Learner Autonomy}

Language retention is warranted in a less direct way by fostering student autonomy, 
by sparking student's interest in the language and its corresponding culture, and by making them understand that the knowledge gained in language classes must be practiced outside. FL learners have to realize how much depends on them because they ultimately have to make the executive decision of whether and how to use the language outside classroom.

Fostering learner autonomy requires an individual approach to each learner and involves teacher's assistance in the development of an individual learning style. The development of student autonomy is based on teacher-learner interaction and cooperation during which they consult decisions concerning the didactic process, they negotiate goals to be achieved by the learner as well as learning types, and they share responsibility for the didactic process. In this sense, the roles of teacher and learner are complementary. The autonomous approach to studying is reflected in students' learning styles and strategies including metacognitive, cognitive, and socioaffective (J.M. O`Malley/ A.U. Chamot 1990 in K. Droździał-Szelest 1997: 38). Metacognitive strategies are related to the organization of the learning process and include functional planning, directed attention, selective attention, self-management, self-monitoring, delayed production as well as self-evaluation. Cognitive strategies which are connected with memorization, more effective understanding and language production comprise: repetition, grouping, imagery, deduction, transfer, elaboration, inferencing, note taking, resourcing, translation, recombination, auditory representation, and contextualization. Finally, socioaffective strategies relate to cooperation with other native speakers as well as with other learners of the foreign language, e.g. questions for clarification and self-talk. All types of learning strategies do not only play an important role in the process of learning, but are also crucial preventive measures against attrition.

Students apply different strategies in the process of language acquisition, depending on their learning preferences, individual goals, and needs. The need to apply individual learning strategies was confirmed by the teachers who had been asked to list the most important qualities of a good language learner (J. Moon 2005: 164). According to them, a successful language learner is someone who takes risks, who is motivated to learn English, creative, well-organized, focused, inquisitive, confident, keen to communicate. Also, this is someone who does not give up easily, eagerly participates in in-class activities, corrects his/her own mistakes, seizes every opportunity to use English and is willing to plan and review his/her work. One of the aforementioned qualities is particularly important in language attrition prevention, namely one's inclination to seize every opportunity to practice the language studied. The role of a teacher in fostering learner autonomy is to introduce learning strategies to the learners, to support their motivation, to learn the language and to encourage them to look for the opportunities to use the foreign language actively. On the other hand, the students' role is to develop their own learning styles and to apply appropriate learning strategies, so as to actively use the language, not only during a language course. We have to emphasize that attempts to promote learner autonomy may work with a different degree of success in different age groups.

Teachers who foster learner autonomy redefine their role in a language classroom, 
share some responsibility with students, and assist learners in the learning process through tasks promoting learner autonomy (e.g., introspecting and retrospecting selfreports, diaries and evaluation sheets). Autonomous students initiate learning which they view as a constructive process that includes actively seeking opportunities to learn. Unfortunately, teachers cannot teach their students how to be autonomous. What they can do instead is to create an environment in which learners will not be afraid to speak the language they study, in which they will be eager to take the necessary risk in order to test and reject hypotheses and rules that do not hold.

In like manner, many FL teachers are FL learners who just like their students need to constantly maintain and develop their language skills. Thus, teachers should not only support their students on the way to autonomy but they also have to develop their own autonomy and apply their individual learning strategies. As argued previously, foreign language teachers' linguistic skills are not immune to attrition. Consequently, they should take steps so as not to let their language skills attrite, act according to their individual learning styles to develop autonomy and take steps to improve or maintain their linguistic skills.

\section{Positive attitude}

The success in language learning relies on learners' attitude towards the world and learning. The more tolerant approach to the target language and its culture the more likely they are to be committed to the task of learning it. Language learning if not appreciated can easily turn into a struggle similar to the one experienced by those who treat any learning activity as an imposition. Positive attitude should be fostered in a language class. Positive attitude toward the language studied should extend beyond formal setting and continue long after the formal acquisition ends. The notion of positive attitude should be extended to learners' willingness to communicate in the target language beyond classroom, to their eagerness to take the necessary risk to strike a conversation with a native speaker, communicate on their own, and to provoke linguistic situations in which they may practice the language. Ultimately, this is how they learn to trust their language skills.

Indeed, different personal factors have been found to correlate with successful non-native language acquisition, for instance high tolerance for lexical and syntactic ambiguity, extrovert character traits, eagerness to leave one's comfort zone and confront one's language skills in the target linguistic environment (T. Reilly 1988). In the US, non-English speaking children learning English who seized every opportunity to communicate with native speakers and practice the skills acquired and those who had a friendly attitude toward native speakers learned the language easier and faster (L. Wong-Fillmore 1985).

\section{Conclusion}

Language attrition is a "powerful force". Formal context of foreign language learning and teaching is not immune to attrition. By understanding attrition, we do not only learn how to prevent it, but we hope to improve the process of foreign language 
teaching as well. FL teachers who are aware of attrition would be able to recognize its early symptoms and apply relevant preventive measures against language loss. On the other hand, FL learners familiar with the phenomenon in question would be further motivated to fully cooperate with the language teacher.

\section{References}

Carr, T.H./ T. Curran (1994), Cognitive factors in learning about structured sequences: Applications to syntax. In: Studies in Second Language Acquisition 16 (2), 205-230.

Cohen, A.D. (1974), Culver City Spanish immersion progress: How does summer recess affect Spanish speaking ability? In: Language Learning 24, 55-68.

Collins, L./ J. White (2012), Closing the Gap: Intensity and Proficiency. In: C. Muñoz (ed.), Intensive Exposure Experiences in Second Language Learning. Clevedon, 45-66.

Collins, L./ J. White/ P. Trofimovich/ W. Cardoso/ M. Horst (2012), When Comprehensible Input Is Not Comprehensive Input: A Multi-dimensional Analysis of Instructional Input in Intensive English as a Foreign Language. In: C. Muñoz (ed.), Intensive Exposure Experiences in Second Language Learning. Clevedon, 66-88.

Droździał-Szelest, K. (1997), Language learning strategies in the process of acquiring a foreign language. Poznań.

Droździał-Szelest, K. (2004), Strategie uczenia się języka obcego: badania a rzeczywistość edukacyjna. In: M. Pawlak (ed.), Autonomia w nauce języka obcego. Poznań/ Kalisz, 31-43.

Edwards, H.P. (1976), Evaluation of the French immersion program offered by the Ottawa Roman Catholic Separate School Board. In: Canadian Modern Language Review 33, 137-142.

Hakuta, K. (1974a), Prefabricated patterns and the emergence of structure in second language learning. In: Language Learning 24, 287-297.

Hakuta, K. (1974b), A preliminary report on the development of grammatical morphemes in a Japanese girl learning English as a second language. In: Working Papers in Bilingualism 3, 18-43.

Holmes, J. (2008), An Introduction to Sociolinguistics. Harlow

Just, M.A./ P.A. Carpenter (1992), A capacity theory of comprehension: Individual differences in working memory. In: Psychological Review 90(1), 122-149.

Kahneman, D. (1973), Attention and Effort. Englewood Cliffs, NJ.

Lamb, S. (1999), Pathways of the Brain: The Neurocognitive Basis of Language. Amsterdam

Leow, R.P./ M.A. Bowles (2005), Attention and awareness in SLA. In: C. Sanz (ed.), Mind and Context in Adult Second Language Acquisition: Methods, Theory, and Practice. Washington, DC, 179-203.

Long, M. (1990), Maturational constrains on language development. In: Studies in Second Language Acquisition 12, 251-285. 
McLaughlin, B. (1984), Second Language Acquisition in Childhood: Vol. 1 Preschool Children (2nd edn). Hillsdale, NJ.

Moon, J. (2005) Children learning English. Basingstoke.

Netten, J./ C. Germain (2000), Transdisciplinary Approach and Intensity in Second Language Learning/Teaching. In: Canadian Journal of Applied Linguistics 3(1/2), $107-122$.

O`Malley, J.M./ A.U. Chamot (1990), Learning Strategies in Second Language Acquisition. Cambridge.

Posner, M.I. (1992), Attention as a cognitive and neural system. In: Current Directions in Psychological Science 1, 11-14.

Reilly, T. (1988), Maintaining foreign language skills. ERIC Digest: MD.

Scherer, G. (1957), The forgetting rate in learning German. In: German Quarterly 30, 275-277.

Schmid, M.S./ T.H. Mehotcheva (2012), Foreign language attrition. In: Dutch Journal of Applied Linguistics 1:1, 102-124.

Schmitt, N. (2007), Current trends in vocabulary learning and teaching. In: J. Cummins/ C. Davison (eds), The International Handbook of English Language Teaching Vol. 2. Dordrecht.

Serrano, R. (2012), Is Intensive Learning Effective? Reflecting on the Results from Cognitive Psychology and the Second Language Acquisition Literature. In: C. Muñoz (ed.), Intensive Exposure Experiences in Second Language Learning. Clevedon, $3-25$.

Shekan, P. (2015), Working Memory and Second Language Performance: A Commentary. In" A. Wen/M. Borges Mota/ A. McNeill. (eds), Working Memory in Second Language Acquisition and Processing. Clevedon, 175-189.

Seliger, H.W./ R. Vago (eds.) (1991), First language attrition. Cambridge.

Smythe, P.C./ G.C. Jutras/ J.R. Bramwell/ R.C. Gardner (1973), Second language retention over varying time intervals. In: Modern Language Journal 57, 400-405.

Stern, H.H. (1976), The Ottawa-Carleton French project: Issues, conclusions, and policy implications. In: Canadian Modern Language Review 33, $216-233$.

Szupica-Pyrzanowska, M. (2016), Language attrition - Implications for second/foreign language acquisition. In: Lingwistyka Stosowana/ Applied Linguistics/ Angewandte Linguistik 16(1), 109-120.

Szupica-Pyrzanowska, M./ K. Malesa (2017), Are they part of the equation? - foreign language teachers versus language attrition. A diagnostic study. In: Theory and Practice of Second Language Acquisition 3/2, 49-68.

Tomlin, R.S./ V. Villa (1994), Attention in cognitive science and second language acquisition. In: Studies in Second Language Acquisition 16 (2), 183-203.

Wang, Z. (2014), On-line time pressure manipulations: L2 speaking performance under five type of planning and repetition conditions. In: P. Shekan (ed.), Processing Perspectives on Task Performance. Amsterdam, 27-62.

Wang, Z./ P. Shekan (2014), Structure, lexis, and time perspective: Influences on task performance. In: P. Shekan (ed.), Processing Perspectives on Task Performance. Amsterdam, 155-186. 
Wickens, C.D. (1980), The structure of attentional resources. In: R.S. Nickerson (ed.), Attention and performance VIII. Mahwah, NJ, 239-257 .

Wickens, C.D. (1984), Processing resources in attention. In: R. Parasuraman/ D. Davies (eds), Varieties of attention. New York, 63-98.

Wickens, C.D. (1989), Attention and skilled performance. In: D. H. Holding (ed.), Human skills. New York, 71-105.

Włosowicz, T.M. (2017), English Language Attrition in Teachers: Questions of Language Proficiency, Language Maintenance, and Language Attitudes. In: Theory and Practice of Second Language Acquisition 3 (1), 75-100.

Wong-Fillmore, L. (1985), Second Language learning in children: A proposed model. In: R. Esch/ J. Provinzano (eds.), Issues in English language development. Rosslyn, VA, 33-42. 